\title{
Research cooperation within the bio-pharmaceutical industry: Network analyses of co-publications within and between firms
}

\author{
Clara Calero，Thed N. van Leeuwen，Robert J. W. Tijssen
}

Center for Science and Technology Studies (CWTS), Leiden University, Leiden (The Netherlands)

\begin{abstract}
Bio-pharmaceutical R\&D is increasingly an international affair. Research articles published in the peer-reviewed international scientific and technical journals represent quantifiable research outputs of bio-pharmaceutical firms. Large-scale systemic measurements of worldwide trends and sectoral patterns within bio-pharmaceutical science can be gauged from these articles, where coauthored research papers are assumed to reflect research cooperation and associated knowledge flows and exchanges. We focus our attention on the largest science-based multinational enterprises (MNEs), those that produce relatively large quantities of research articles. The study deals with the worldwide output of research articles that are co-produced by corporate researchers during the years 1996-2001.

We employ these publications to examine structural factors characterizing research cooperation networks within industry at the level of major geographical regions (North America, Europe, Pacific-Asia), with a breakdown by within-MNE and between-MNE network linkages. The descriptive statistics on publication output and results of network analyses of co-publication linkages not only indicate regional differences, with a central role for US companies in biopharmaceutical research, but also a variety of firm-specific research cooperation networks which enabled us to develop a tentative typology of MNEs in terms of their intra- and interorganizational patterns of research cooperation linkages.
\end{abstract}

Received June 2, 2006

Address for correspondence:

Clara Calero

Center for Science and Technology Studies (CWTS), Leiden University

P. O. Box 9555, 2300 RB Leiden, The Netherlands

E-mail: clara@cwts.nl

0138-9130/US $\$ 20.00$

Copyright (0) 2007 Akadémiai Kiadó, Budapest

All rights reserved 


\section{Introduction}

Many of the largest bio-pharmaceutical firms face spend approximately $15 \%$ of their sales on $R \& D$; in some cases their annual R\&D costs amount to billions of euros. The globalization of markets, the regionalization of technical and scientific knowledge, scientific progress in the biomedical sciences, and the complexity of drug discovery processes, are forcing these companies to disperse their $R \& D$ organization and engage increasingly in $\mathrm{R} \& \mathrm{D}$ partnerships to access all the required knowledge and technologies. At the same time, as HowELLS (1990) points out, modern information and communication technologies serve to connect disseminated R\&D activities and thus made distributed R\&D organization possible. Because the bio-pharmaceuticals sector is often leading the way in this process of internationalization in their continual search for applicable knowledge and first-rate partners for their drug discover research, we are going to focus our attention on the large science-based multinational enterprises (MNEs) that are active in the bio-pharmaceuticals sector and produce relatively large numbers of research articles - either with partners within the MNE and/or with external partners within the private sector.

During the last two decades, the bio-pharmaceuticals industry has shifted its basic research operations from trial-and-error drug discovery approaches to a more sciencebased deductive method of searching for new target receptors and molecules that inhibit the target (e.g. Arora \& Gambardella, 1994; Henderson \& COCKBURN, 1994; NightingALE, 2000). As a result, the ties between biotechnology companies and biopharmaceuticals companies have become close, and new organisational forms emerged to conduct basic bio-pharmaceutical research.

Traditionally a MNE's most strategic 'core' research activities were concentrated in a central R\&D laboratory which was usually located in the home country. Nowadays, these elaborate organizational structures to enable research collaborations are determined and influenced by a wide range of factors, including the company's internal distribution and allocation of R\&D resources (GASSMANN \& VAN ZEDTWITZ, 1999; 2002), access to locally based technological expertise (CANTWELL \& JANNE, 2000), the role of local or national governments in partnership promoting initiatives, as well as business strategies impacting on the propensity towards cooperation; outsourcing of research, or engaging in both horizontal (within-MNE) or vertical (external) research collaboration.

Clearly there are immense methodological problems in systematically analysing the organizational and geographical characteristics of R\&D activities by MNEs. Measuring and comparing their research cooperation networks is notoriously difficult. Many of these measurement problems relate to the scale, and levels of importance, of research cooperation, and the ways in which the objectives of research cooperation and networks can change over time. A solution for this dilemma is the application of empirical 
evidence extracted from the contents of scientific and technical articles that are authored industrial researchers and published in the peer-reviewed international scientific and technical journals. Although companies may publish for a large variety of reasons (TIJSSEN, 2004), one of which is to leverage results of their research as an interface to the global research community (HICKS, 1995), in most cases these articles reflect knowledge creation and knowledge transfer processes within corporate research labs. ${ }^{1}$ The affiliate addresses of the author(s) listed on these research articles enable comparative analyses at the level of individual companies and their countries of location (e.g. TIJSSEN et al., 1996; GODIN, 1996). Especially the big pharma companies publish sufficiently large annual quantities of research articles in the journal literature to warrant company-level (trend) analyses of research output related characteristics. A score of empirical studies have drawn on publication counts as an important indicator of research activity in the pharmaceutical industry (e.g. KOENIG, 1983; NARIN \& ROZEK, 1988; GAMBARDELla, 1995; MCMILlan \& HAMILTON, 2000; CoCKBURN et al., 2000; D’ESTE, 2005).

A significant share of industry's research articles list co-authors based at other affiliations within the same (parent) company, other companies, and/or public research organizations. This information source also enables aggregate-level quantitative information on patterns of research collaboration and related knowledge-spillovers. ${ }^{2}$ We use these co-publications to examine structural factors that impact on research cooperation within and between companies. These research cooperation networks can be examined systemically by creating connectivity indicators based on these copublications, thus showing relationships and linkages between the various actors and agents involved in joint scientific research. The network analyses of co-publication linkages indicate structural differences between types of MNEs, which enabled us to develop a general typology of MNEs in terms of their patterns of research cooperation linkages.

\section{Data collection and methodology}

The research publications that were analysed for this study were extracted from CWTS's Corporate Research Papers (CRP) database, a subset of research articles published in international scientific and technical journals that are covered by the

\footnotetext{
${ }^{1}$ This source of printed 'codified knowledge' not only reflects "discovery" research done with the labs of the bio-pharmaceutics companies, but also related experience-based 'tacit' knowledge and the related skills base (e.g. Mowery et al., 1996).

${ }^{2}$ Co-authoring scientific publications is one of the clearest links to informal networking that can be made. These joint research papers reflect successful scientific co-operation and are likely to signify related knowledge flows and research networking activity between companies. Nevertheless, co-publication statistics and indicators should be handled with due care as a reliable source of conclusive empirical evidence on actual scientific cooperation (e.g. KATZ \& MARTIN, 1997).
} 
CWTS-licensed CD-Rom Edition of Thomson Scientific's Citation Indexes, in which at least one of the affiliate addresses of the authors refers to a private sector organization (see Tijssen, 2004). ${ }^{3}$ A co-authored paper is fully credited to all firms listed in the author address information. ${ }^{4,5}$ The bio-pharmaceuticals companies included in this study were selected according to their presence of at least one of their business unit or subsidiaries in Dunn \& Bradstreet's "Who owns Whom" database (edition 2003), and the (parent) company's volume of (co-authored) research articles that were indexed in the CRP database. First, all business units/subsidiaries with Standard Industrial Code (SIC) code 2834 ("Drugs") were selected. ${ }^{6}$ Then, all the (parent) companies of those business units/subsidiaries were selected that published at least five research articles during the years 1996-2001. ${ }^{7}$ The companies that are represented in this set of publications were mostly (very) large pharmaceutical firms, especially the MNEs that invest heavily in their own research capabilities and sustain $R \& D$ labs that also perform original cutting-edge scientific research. One of the main characteristics of this set of papers is that $55.6 \%$ of the publications where produced by companies located in North America, including the Canadian companies. ${ }^{8}$

Each standardised name of the (parent) company was linked to the country of the company's location, i.e. the country of origin listed in the author affiliate address information in the research article. These company/country pairs enabled us to identify

\footnotetext{
${ }^{3}$ The CRP includes some 350,000 research papers published in 1996-2005 and (partially) assigned to the private sector. The coverage extends across all countries and fields of science and some 40,000 different main organizations are covered. Foreign branches and foreign subsidiaries of multinational companies are labelled with the consolidated name of the parent company. Companies that were added to the parent company through mergers and acquisitions were renamed to the current (ultimate) parent company to ensure backwards and forwards compatibility in trend analyses.

${ }^{4}$ Dividing a paper between the participating units (researchers, organizations, countries) is to some extent arbitrary - there is no fair method to determine how much money, effort, equipment and expertise each entity contributes the underlying research effort and writing the paper. Our basic assumption therefore is that each author, and associated corporate affiliate, made a non-negligible contribution.

${ }^{5}$ All co-publications are treated similarly in the statistical analyses, irrespective of the number or type of organisations (private or public sector) listed in the author address information. As a result, a co-publication listed two or more different (parent) companies may or may not include addresses referring to public sector organisations.

${ }^{6}$ Given the variety of SIC codes assigned to the different business units of the same (parent) company, many corporate affiliates were therefore allocated to several of the industrial sectors. The selection and matching procedure was carried out by CWTS in cooperation with CESPRI (Bocconi University, Milan, Italy).

${ }^{7}$ The data for this study were taken from the European project 'Network Indicators: Science, Tecnology and Innovation (STI-NET)". The STI-NET Project started on January 15th 2002 and was a 30 months project. The partners were CESPRI - Centre for Research on Innovation and Internationalisation Processes, Università Luigi Bocconi, Italy, MERIT - Maastricht Economic Research Institute on Innovation and Technology, University of Limburg, The Netherlands and the CWTS - The Centre for Science and Technology Studies, University of Leiden, The Netherlands. The aim of the research project was the identification, construction, and analytical use of network indicators in science, technology and innovation.

${ }^{8}$ For comparison, the US accounted for $31 \%$ of all research publications worldwide across all fields of science in 1998 and 2001 (EC, 2003), considerably less than its 55.6\% share of corporate research papers in the bio-pharmaceutical industry.
} 
separate national affiliates of the (parent) companies (e.g. "Bayer AG/Germany" and "Bayer Corp/USA"), either the company headquarters in the home country or foreign subsidiaries. These company-country combinations are referred to as "corporate affiliates" hereafter. This breakdown by country enabled us to analyze and interpret copublication data both in terms of intra-organizational collaboration (within the parent company "Bayer") as well as inter-organizational research partnerships (between different parent companies).

The last step to get the final core set of publications was to extract from the CRP database all the research papers that list at least two addresses referring to two selected corporate affiliates. The companies that took part on this set of publications were mostly (very) large pharmaceutical firms, especially MNEs. In total, there were 378 corporate affiliates. The resulting co-publication frequencies for each pair of affiliates were collected in a data array that was fed into the UCINET software package (BORGATTI et al., 2002) that performs a network analysis providing statistics and graphical representations of the network structure.

\section{Main results}

\section{Distribution of co-publication partnerships by region}

Using the geographical distribution of research partners listed on joint research papers, either within the same (ultimate) parent firm, or between firms, enabled us to estimate the degree of internationalization of corporate research cooperation. The breakdown by broad geographic region in Table 1 indicates that corporate research partnering within the pharmaceutical sector has become truly globalized at the end of the $20^{\text {th }}$ century. Not only, do we also observe a particularly large propensity for tripartite cooperation, with partners spread across three regions, which account for $15 \%$ of the co-publications, we also find $8 \%$ of the co-publications listing partners in four different regions. The majority of the relationships across three of four regions refer to connections between North America, EU-15, and the Other European countries, the latter being largely a result of large MNEs based in Switzerland.

How can this degree of globalization and these geographical variations be explained? The above findings are obviously significantly affected by the geographically diversified science-based MNEs with R\&D-labs scattered around the globe. Overall, we find a dominant role of North American companies in the transregion research cooperation, which is in part due to the attractive assets offered by US biotechnology companies in terms of their information sources, new approaches and advanced capabilities. ${ }^{9}$

\footnotetext{
${ }^{9}$ One of the major strengths of the US bio-pharmaceuticals industry lies in its specialization in bio/gene technologies for drug discovery in the fields of immunology and oncology.
} 
C. CALERO et al.: Bio-pharmaceutical industry

Table 1. Corporate co-publication partnerships by number of regions involved,

\begin{tabular}{lc}
\multicolumn{1}{c}{ Location of research partners } & Share of all co-publications (\%) \\
\hline Within regions - total & 46 \\
Within North America (NA) & 24 \\
Within Europe - EU-15 & 12 \\
Within Pacific Asia & 10 \\
Within Europe-Others & 0 \\
& \\
Two regions - total & 31 \\
NA + EU-15 & 18 \\
NA + Pacific Asia & 5 \\
NA + Europe-Others & 2 \\
EU-15 + Europe-Others & 3 \\
EU-15 + Pacific Asia & 3 \\
& \\
Three or four regions - total & 23 \\
NA + EU-15 + Europe-Others & 9 \\
NA + EU-15+Europe-Others + Pacific Asia & 7 \\
NA + EU-15 + Pacific Asia & 6 \\
NA + Europe-Others + Pacific Asia & 1 \\
\hline
\end{tabular}

This geographically diversified science-base is also influenced by the scattering of the research performing companies. Out of a total of 378 affiliates: $42 \%$ were North American-based; 37\% were located in EU-15 countries; $18 \%$ in the Pacific Asia region (mainly Japan and Taiwan, and excluding Australia); 2\% were based in 'Other European countries', principally in Switzerland, Norway, and Israel, ${ }^{10}$ and only $1 \%$ were assigned to 'other countries' which refers to companies located in Australia.

The main determining factor for the North American surplus and deficits of copublication outputs by the other regions clearly the size of the (science-related) industrial base of each region. In terms of sheer magnitude, we note the marked dominance of North American-based affiliates (US and Canada) as a consequence from the combination of several factors: (1) the size of US industry in the sectors, (2) the scale of their research activity, (3) their propensity for research cooperation, (4) their propensity to publish research findings in the open scientific literature. These factors are obviously difficult to unravel empirically at an aggregate level, let alone at the company level, a second explanatory determinant can be gleaned from further breaking down the partnerships geographically.

${ }^{10}$ Israel was considered an European country in this study. 
Table 2 exhibits the breakdown of co-publications by geographic location of research partners. First, we observe a strong tendency towards corporate research partnering within the region. The majority of the co-publication partners of each of the major regions (North America, Europe, and Pacific Asia) are located within the same region, which is to a large degree the logical consequence of proximity effects due to common (domestic) research systems, share language and culture, or the regional scope of business activities. However, we do find a relatively low share of within-region partnerships within the EU-15 in comparison to North America, which suggests that the European pharmaceutical industry less affected by proximity effects. One of the reasons for this difference is the US-orientation of the large Swiss bio-pharmaceutical MNEs (for example Novartis, which is further discussed in the next section). Interestingly, these non-EU-15 companies prefer North America partners even more than EU-15 counterparts. Another possible explanation for Europe's extra-regional orientation relates to the presence of affiliates of non-European MNEs within Europe; these foreign affiliates tend to engage in intra-MNE cooperation with other affiliates located outside Europe (as illustrated in the examples provided in the next section).

Table 2. Within-region and between-region research collaboration between corporate affiliates 1996-2001 (row percentages)

\begin{tabular}{lcccccc}
\hline & \% within-region & \multicolumn{2}{c}{$\%$ partners in other regions } & & \\
Location of affiliate & partnerships & NA & EU-15 & Europe-Other & Pacific Asia & Other \\
\hline North America (NA) & 75 & & 16 & 4 & 2 & 3 \\
Europe - EU-15 & 52 & 37 & & 8 & 3 & 0 \\
Europe - Other & 12 & 48 & 37 & & 4 & 0 \\
Pacific Asia & 66 & 19 & 12 & 3 & 0 & 0 \\
\hline
\end{tabular}

When analyzing the intra-MNE organisational dimension of research networks, size does seem to matter. Considering their large share of the corporate research literature worldwide, the US-based affiliations seem to have relatively many domestic partners. The domestic orientation of the USA is in part explained by the scale and diversity of the US corporate sector, which comprises of an almost self-contained R\&D base. We find a significant overrepresentation of the EU-15-based affiliates in research partnerships, which is in large part due to the European affiliates of US companies. Remarkable is the relatively small share of partnerships between North America and the companies in Pacific Asia. This deviant result might reflect cultural differences, where Western companies tend to adopt relatively "open" R\&D models with international cooperative structures whereas MNEs with headquarters based in Japan and South Korea prefer more "closed" structures that favour cooperation across close geographic proximities. In contrast, the EU-15 based MNEs are much less regionally focused. Next, we observe remarkably low intra-regional cooperation propensities within the affiliates based in the Other European countries, which is no doubt due to the small size of the domestic industrial base - hence, few (potential) research partners - and partially a 
result of the industrial sector structure which is dominated by a few large multinational affiliates with branches and R\&D labs worldwide (e.g. Swiss-based pharmaceutics companies).

\section{Research collaboration network patterns}

Only 35 companies (accounting for 129 corporate affiliates) are in fact MNEs exhibiting co-publication links between their various affiliations (i.e. company headquarters and subsidiaries/branches in different countries). The remainder comprises multinational enterprises with only one research facility or R\&D laboratory that is producing research papers, and national enterprises with no foreign affiliations. Starting from the arrays of co-authorship frequencies, the co-publication linkages between the MNE's headquarters and its foreign subsidiaries are identified and the various nodes (circles), each representing corporate affiliates, are connected. Each link between the nodes indicates one or more co-authored research publications. Co-publication links to affiliates of other companies are represented by squares.

Focusing on the structural features of the co-publication patterns of those 31 'networked' MNEs, we identify three general types of co-publication networks characterizing the relationships between headquarters and subsidiaries of the same company: (1) centralized networks, (2) decentralized networks, and (3) gateway networks.

Centralized corporate research network. This particular kind of network consists of co-publications involving the company headquarters (i.e. central R\&D laboratory) and its affiliates, as well as their co-publishing activity with other companies that tend to concentrate at the company headquarters. This set includes 14 MNEs. Figure 1 displays an illustrative example of this type of centralized network for the case of Bayer. All of Bayer's subsidiaries co-published with the headquarters in Germany, as well as with Bayer labs in the USA. The headquarters, USA and Great Britain all have research collaborations with other firms based in the EU-15, in other European countries and in North America. Bayer/Japan extends this network with additional collaborations with companies in its own region.

Decentralized corporate research networks. This category comprises of networks that are characterized by the lack of (strong) links between the company headquarters (i.e. central research laboratory) and subsidiaries that do not co-publish. Rather, each research laboratory co-publishes with other companies located in the different regions of the globe. The pattern reflects a corporate R\&D strategy with geographically dispersed and (semi) autonomous research laboratories. About 14 of the 31 MNEs can be attributed to this category. Figure 2 shows then network of Novartis. Novartis' headquarters are located in Switzerland with several subsidiaries scattered across the globe. 


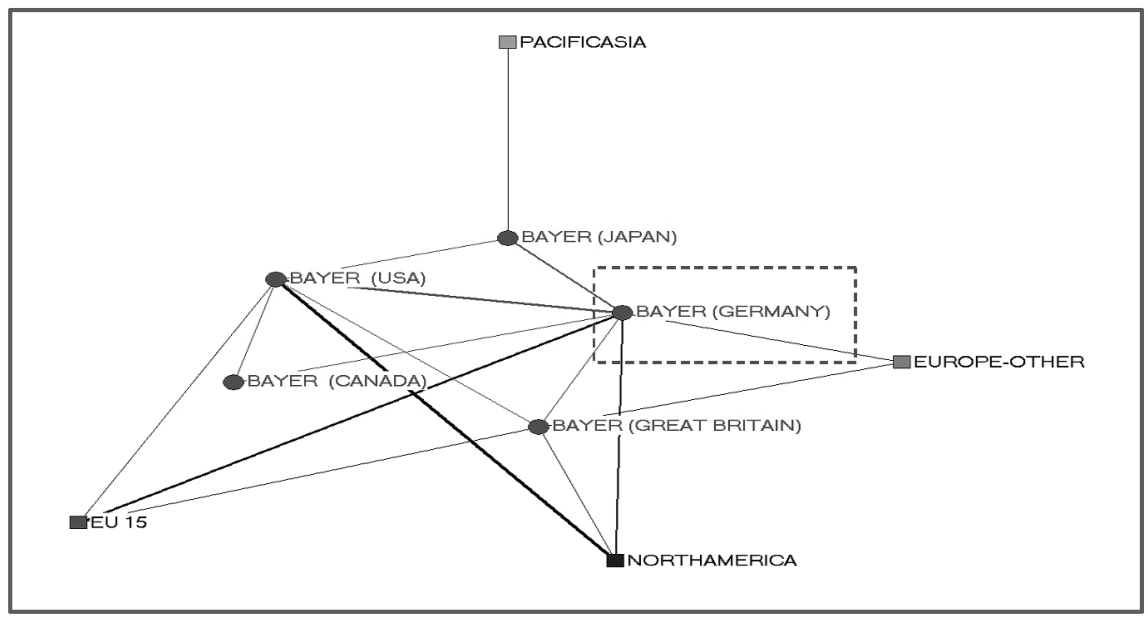

Figure 1. Centralized corporate research network: Bayer

Circles - Country of location of corporate affiliates belonging to the same multinational enterprise. Squares - Region of location of external partners in research co-publications. The thickness of the connecting line indicates the quantity of co-publications

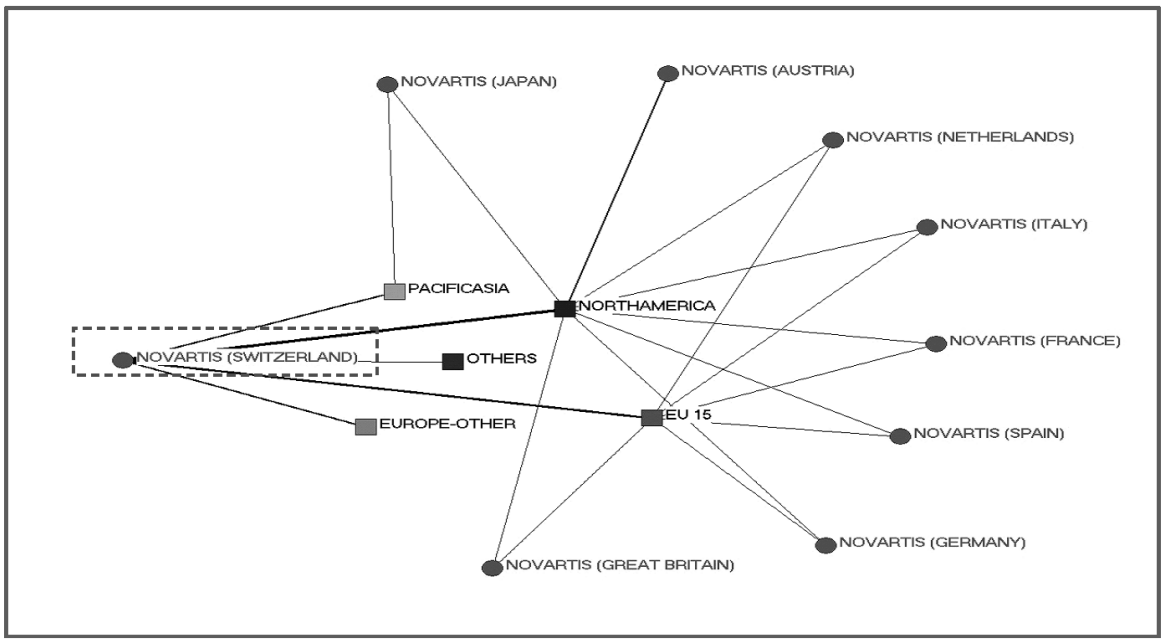

Figure 2. Decentralized corporate research network: Novartis

Circles - Country of location of corporate affiliates belonging to the same multinational enterprise. Squares - Region of location of external partners in research co-publications.

The thickness of the connecting line indicates the quantity of co-publications 
Novartis Switzerland is connected with all regions, with an especially strong link to Novartis' operations in the EU-15 and the North America region. We can see how each of the subsidiaries have their own pattern of collaboration, sometimes focused on EU15 and North America region, as the case of Novartis' research in Netherlands, Italy, France, while others focus more on Pacific Asia and North America region, like in the case of Novartis research activities in Japan.

Gateway corporate research network. This kind of network is characterized by researchers and scientists at the company's subsidiaries co-publishing exclusively with their colleagues based at headquarters/central R\&D facility, while the latter also copublish with external partners. Only a small minority of the 31 companies appears to operate through these gateway networks. This rare kind of network is characterized by researchers and scientists at the company's subsidiaries co-publishing exclusively with their colleagues based at headquarters/central R\&D facility, while the latter also copublish with external partners. Figure 3 displays the example of Baxter Healthcare, a US company with two subsidiaries that run research facilities - Baxter Germany and Baxter Belgium. Each subsidiary co-publishes with their headquarters, which in turn copublishes also with other companies located elsewhere, North America and EU-15.

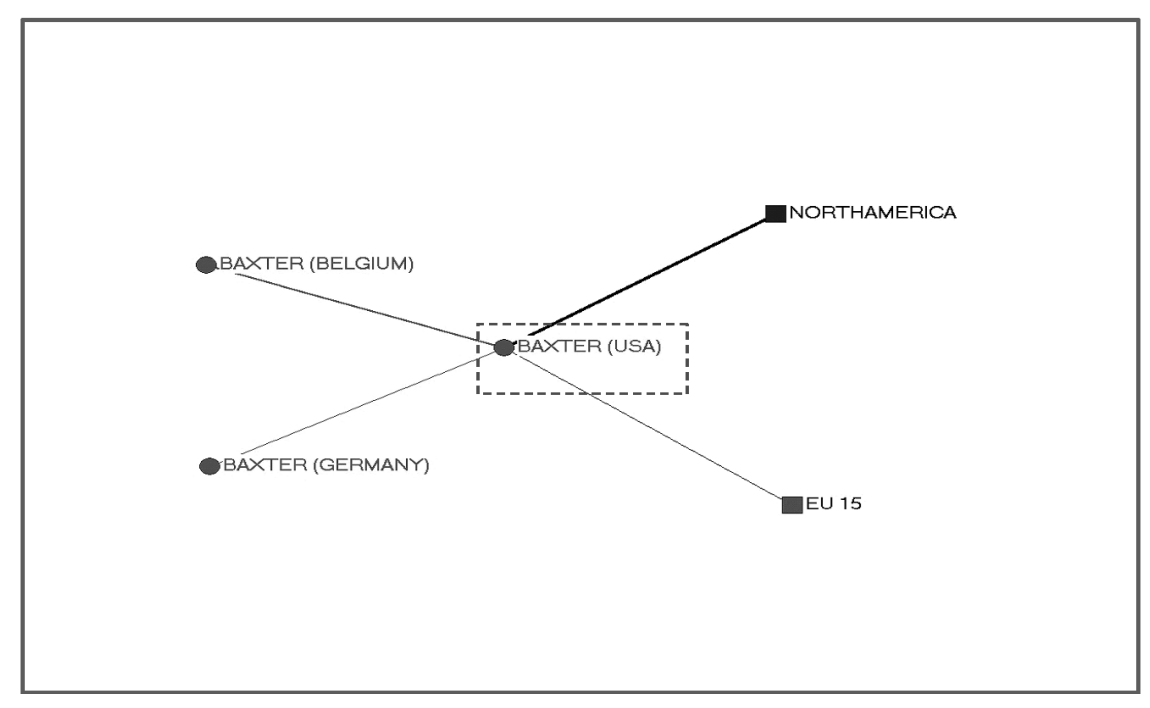

Figure 3. Gateway corporate research network: Baxter

Circles - Country of location of corporate affiliates belonging to the same multinational enterprise.

Squares - Region of location of external partners in research co-publications.

The thickness of the connecting line indicates the quantity of co-publications 


\section{Discussion and concluding remarks}

This empirical study set out to explore the analytical potential of corporate research articles as a source of empirical information for describing structural patterns of research joint ventures (RJVs) within the bio-pharmaceutical industry worldwide, and to produce quantitative data on those research cooperation relationships at the level of countries and major bio-pharmaceutical firms. Given the overwhelming significance of basic research in the bio-pharmaceutical industry, and the large quantity of corporate research papers produced each year, we believe than these publications reflect key characteristics of research cooperation patterns within the industry. The pivotal position of the USA in the bio-pharmaceuticals research output, and the associated global research network, is not surprising in view of the US dominance in the biopharmaceutical sector. More interesting is the particularly strong link we observe between US companies and their research partners in EU-15 countries - either with overseas affiliations of these US companies or external partners. At the firm level, we discerned two types of links: (1) those amongst corporate affiliations belonging to the same (parent) company, and (2) linkages between affiliations of different (parent) companies. The outcome revealed interesting empirical information both with respect to the organizational features of corporate research partnerships within and between companies, as well as geographical dispersion of these partnerships. The company-level breakdown of these cooperation patterns also reveals a variety of intra-firm and extrafirm research linkages, from which three main types of corporate research networks can be derived in terms of the intra-firm distribution of research partnerships: (a) centralized networks, (b) decentralized networks, and (c) gateway networks. The first two types seem to be by far the most common ones.

It stands to reason that the various types of within-firm linkages are driven by different corporate "logic" governed by the prevailing R\&D objectives and constraints, intellectual property rights and knowledge appropriation regimes, and research cooperation motives. Moreover, some of the large pharmaceutical companies nowadays adopt "open" innovation structures, where R\&D cooperation and networking both within and outside the company become increasingly integrated, especially between 'big pharma' companies and smaller biotechnology companies (a recent example is the relationship between Roch, the Swiss company, and the UK biotech firm Antisoma). The joint research publications emerging from these pharma-biotech RJVs have not been included in this study owing to the relatively low numbers of papers.

It is also important to note that many of these research partnerships, and the corresponding co-publications, may also include partners from public sector research organisations and universities (TIJSSEN, 2004). These contributions were not included in the network analysis presented in this paper and are left to future research. Nonetheless, the presence of public sector researchers in 'corporate' RJVs raises questions about the 
nature of the research links between the various corporate affiliations; to what degree these were predominantly curiosity-driven 'academic' partnerships, industry-driven 'application-oriented' partnerships, or a mixture of both? Each type of collaboration is likely to operate according to their own rationale, with different sets of (ultimate) goals and deliverables. Generally speaking, these joint research articles should be viewed as reflecting research cooperation at the work floor level. As such, they are more likely to describe 'informal' research linkages and networking processes between individual researchers, rather than representing the key results of 'formalised' and targeted alliances between $R \& D$ departments or research teams within firms. As a consequence, the structural characteristics of co-publication networks, as depicted in our graphs, are therefore not likely to correspond or correlate with senior management's view of its networking activity in the same way as linkages based on corporate $R \& D$ alliances. We would argue that a publications-based view of corporate research is in fact one of the strengths of our approach, in the sense that it helps external analysts get closer to the joint research products emerging from the day-to-day operations of scientists and technicians employed by the research labs of the bio-pharmaceutical companies.

To conclude, although our empirical data shed some light on corporate research partnering in the bio-pharmaceutical industry, especially within large science-intensive multinational enterprises, we still know little about the detailed and hard-to-observe mechanisms and organizational conditions giving rise to research articles produced by corporate researchers in collaboration with colleagues. Case studies of individual pharmaceutical companies, such as recent studies conducted by CRISCUOLO \& NARULA (2005) or CRISCUOLO (2005), constitute important next steps to help gain insideinformation to unravel the country-specific, firm-specific and person-specific determinants that impact on the reasons for engaging in research cooperation and the propensity to produce the (joint) research articles we have analyzed in this study.

Part of research described in this paper relates to the STI-NET project that was funded by European Commission [Contract HPV2-CT2001-00014] in which CESPRI (Univ. Bocconi, Milan, Italy), MERIT (Univ. Maastricht, Netherlands) and CWTS participated.

\section{References}

Arora, A., Gambardella, A. (1994), The changing technology of technological change: general and abstract knowledge and the division of the innovative labour. Research Policy, 23 : 523-532.

Borgatti, S. P., Everett, M. G., Freeman, L. C. (2002), Ucinet 6 for Windows. Harvard: Analytic Technologies.

Brusconi, S., Crisculolo, P., GeunA, A. (2005), The knowledge bases of the world's largest biopharmaceuticals groups: what do the patent citations to non-patent literature reveal? Economics of Innovation and New Technology, 14 : 395-415. 
CANTwell, J., JANNE, O. (2000), The role of multinational corporations and national states in the globalization of innovatory capacity: the European perspective. Technology Analysis and Strategic Management, $12:$ 243-262.

Cockburn, I. M., Henderson, R. M., Stern, S. (2000), Untangling the origins of competitive advantage. Strategic Management Journal, 21 : 1123-1145.

CoOmbs, R., GeORGHIOU, L. (2002), A new "Industrial Ecology”. Science, 296 : 471.

CRISCUOLO, P. (2005), On the road again: Researcher mobility inside the R\&D network. Research Policy, 34 : 1350-1365.

Criscullo P., NARUlA, R. (2005), Using Multi-hub Structures for International R\&D: Organizational Inertia and the Challenges of Implementation, Working paper.

D'Este, P. (2005), How do firms' knowledge bases affect intra-industry heterogeneity? An analysis of the Spanish pharmaceutical industry. Research Policy, 34 : 33-45.

EC (2003), Third European Report on Science and Technology Indicators: Towards a Knowledge-Based Economy. Brussels: European Commission, Report EUR 200025.

Gambardella, A. (1995), Science and Innovation. The US Pharmaceutical Industry during the 1980s. Cambridge University Press, Cambridge.

Gassmann, O., vON ZEDTwitZ, M. (1999), New concepts and trends in international R\&D organization. Research Policy, $28: 231-250$.

Godin, B. (1996), Research and the practice of publication in industries. Research Policy, $25: 587-606$.

HAGEdoORn, J., LinK, A., VonORTAS, N. (2000), Research partnerships. Research Policy, 29 : 567-586.

Henderson, R., CockBuRn, I. (1994), Measuring competence? Exploring firm effects in pharmaceutical research. Strategic Management Journal,15 (Winter) : 63-84.

HiCKS, D. M. (1995), Published papers, tacit competencies and corporate management of the public/private character of knowledge. Industrial and Corporate Change, 4 : 401-424.

Howells, J. (1990), The location and organisation of research and development: new horizons. Research Policy, 19 : 133-146.

JAFFE, A. (1989), Real effects of academic research. American Economic Review, 79 : 957-970.

KATZ, J. S., MARTIN, B. R. (1997), What is research collaboration? Research Policy, 26 : 1-18.

KoEnIG, M. E. D. (1983), A bibliometric analysis of pharmaceutical research. Research Policy, 12 : 15-36.

MCMillan, G. S., HAMILTON, R. D. (2000), Using bibliometrics to measure firm knowledge: An analysis of the US pharmaceutical industry. Technology Analysis and Strategic Management, 12 : 465-475.

Mowery, D. C., OXley, J. E., Silverman, B. S. (1996), Strategic alliances and interfirm knowledge transfer. Strategic Management Journal, 17 : 77-91.

NARIN, F., ROZEK, R. P. (1988), Bibliometric Analysis of bibliometric analysis of united-states pharmaceutical-industry research performance. Research Policy, $17: 139-154$.

Nightingale, P. (2000), Economies of scale in experimentation: Knowledge and technology in pharmaceutical R\&D. Industrial and Corporate Change, $9: 315-359$.

PAVITT, K. (1998), The social shaping of the national science base. Research Policy, 27 : $793-805$.

Tijssen, R. J. W., VAN LeEuwEN, TH. N., KorevaAR, J. C. (1996), Scientific publication activity of industry in the Netherlands. Research Evaluation, $6: 1-15$.

TIJSSEN, R. J. W. (2004), Is the commercialisation of scientific research affecting the production of public knowledge? Global trends in the output of corporate research articles. Research Policy, 33 : 709-733.

ZEDTwitZ, M. vON, GASSMANN, O. (2002), Market versus technology drive in R\&D internationalisation: four different patterns of managing research and development. Research Policy, 31 : 569-588. 